Ihre Fragen zur Abrechnung und zur wirtschaftlichen Praxisführung beantwortet unser Experte Helmut Walbert, Würzburg.

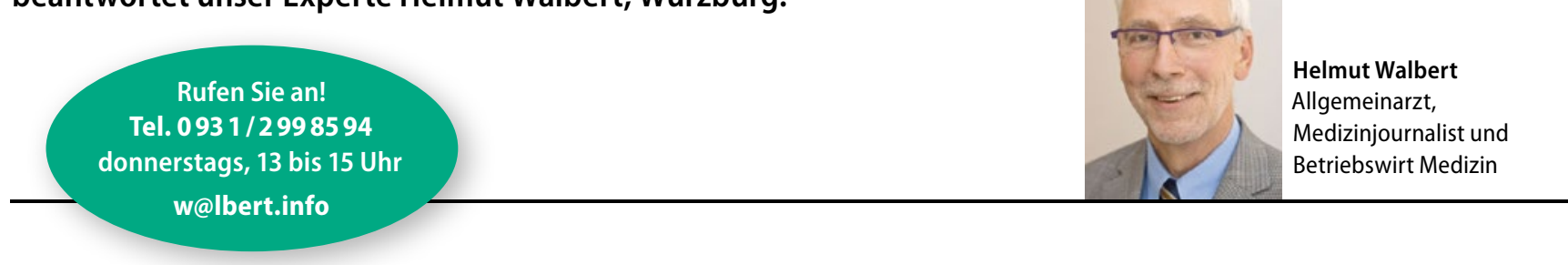

\title{
Ich soll ohne Beratung Regress zahlen
}

? Dr. P. W., Landarzt, Nordrhein: Ich habe vom Prüfungsausschuss einen Regress angedroht bekommen, ohne dass ich zuvor beraten wurde. Ist das nicht eigentlich Pflicht?

MMW-Experte Walbert: Es ist richtig, dass seit dem 1. Januar 2012 der Grundsatz „Beratung vor Regress“ gilt. Diese Regelung ist vor allem für junge
Niedergelassene gedacht, die zum ersten Mal in die Prüfung geraten.

Für länger Niedergelassene, die schon seit Jahren die Richtgrößen überschreiten und Regresse zahlen mussten, gilt dies bei einer erneuten Richtgrößenüberschreitung nicht mehr! Das hat das Bundessozialgericht entschieden (Az.: B 6 KA 3/14 R). Hier besteht nur die Möglichkeit, die Überschreitung so gut

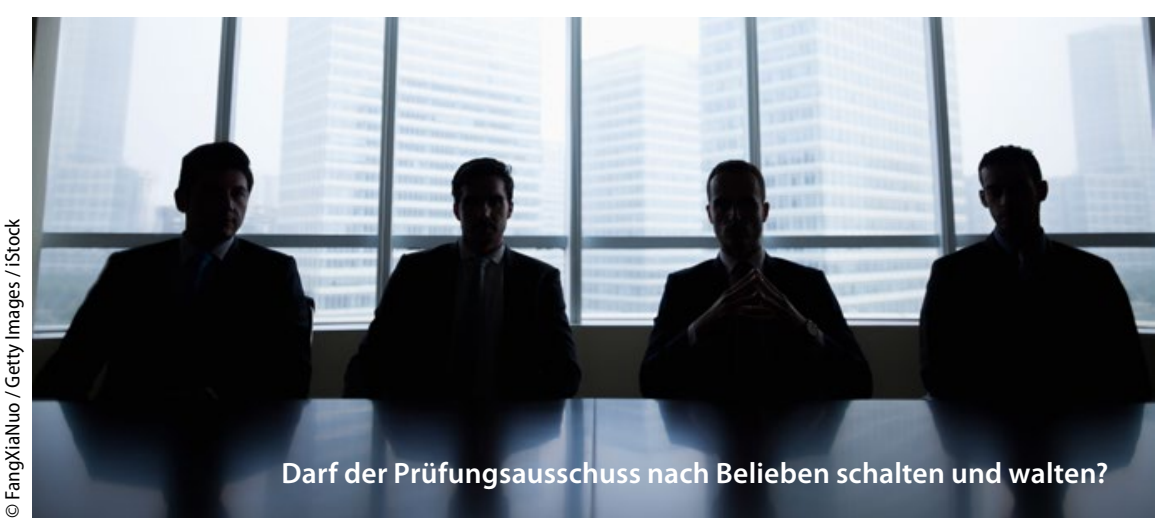

wie möglich plausibel zu erklären, um eine Regresszahlung zu verkürzen oder gar zu verhindern.

Anders sieht die Situation aus, wenn in den Jahren seit 2012 nach erfolgter Beratung ein Regress ausgesprochen wurde. Ist ein Vertragsarzt dann aber in der Lage, seine Überschreitung zu begründen und den Regress so abzuwenden, ist damit seine wirtschaftliche Verordnungsweise bewiesen. Sollte er danach erneut die Richtgrößen überschreiten, hat er erst einmal Anspruch auf eine erneute Beratung. In dieser kann er möglicherweise seine Wirtschaftlichkeit erneut darlegen - und der Regress ist erneut vom Tisch.

Sollte es dann irgendwann noch einmal zu einer Beratung kommen, obwohl die Situation in der Praxis unverändert ist, kann der Vertragsarzt auf Unterlassung klagen - weil die Gremien offensichtlich die dargelegten Praxisbesonderheiten ignorieren.

\section{Akupunkturnadeln einzeln berechnen?}

$?$

Dr. U. K., Hausarzt-Internist, Thüringen: Wir erbringen in unserer Praxis Akupunkturleistungen. Dabei frage ich mich immer, ob ich die $\mathrm{Na}$ deln nicht abrechnen kann. Für die GKV-Leistungen scheint mir der Fall klar zu sein, da im EBM ausdrücklich festgehalten ist: „Die Sachkosten inklusive der verwendeten Akupunkturnadeln sind in der Gebührenord- nungsposition 30791 enthalten." Gibt es Fälle, in denen ich Sachkosten verrechnen kann?

MMW-Experte Walbert: Grundsätz- lich geht das nur außerhalb der GKV, also bei Akupunkturleistungen, die als Individuelle Gesundheitsleistungen (IGeL) oder bei privat Versicherten nach GOÄ abgerechnet werden.
Akupunktur-IGeL werden grundsätzlich nach den Nrn. 269 oder 269a GOÄ abgerechnet. Auch hier gilt, dass Sachkosten nach $\$ 10$ der GOÄ als Ersatz von Auslagen in Rechnung gestellt werden. Akupunkturnadeln sind in den aufgeführten Einmalmaterialien, die als Allgemeinkosten der Praxis nicht berechnet werden dürfen, nicht aufgezählt - und somit berechnungsfähig. 